\title{
Aggression and Peer Rejection among Children with Conduct Disorder
}

\author{
Somaieh Salehi ${ }^{1}$, Sidek Mohd Noah ${ }^{1}$, Maznah Baba ${ }^{1}$ \& Wan Marzuki Wan Jaafar ${ }^{1}$ \\ ${ }^{1}$ Department of Counselor Education and Counseling Psychology, Faculty of Educational Studies, Universiti \\ Putra Malaysia, Malaysia \\ Correspondence: Somaieh Salehi, Department of Counselor Education and Counseling Psychology, Faculty of \\ Educational Studies, Universiti Putra Malaysia, Selangor, 43300, Malaysia. Tel: 60-16-686-1303. E-mail: \\ somaieh19salehi@gmail.com
}

Received: January 8, 2013 Accepted: February 25, 2013 Online Published: March 28, 2013

doi:10.5539/ass.v9n4p133 URL: http://dx.doi.org/10.5539/ass.v9n4p133

\begin{abstract}
Children with Conduct Disorder suffer from aggression and peer difficulties. This study provides an overview of aggression and peer rejection among children with Conduct Disorder worldwide and in Iran. This study is based on researches from library archives specially focused on studies have been done in Iran. First Conduct Disorder, its' prevalence, subtypes, and other comorbid disorders are explained. Next, studies regarding aggression among aggressive children and children with conduct problems are reviewed. In this part, the social cognitive deficits of these children are presented based on the model of Social Information Processing. The study followed by researches about peer rejection among children with $C D$. In addition studies of children with CD in Iran were reconsidered.
\end{abstract}

Keywords: conduct disorder, aggression, peer rejection

\section{Introduction}

Conduct Disorder (CD) is one of the forms of externalizing disorder listed in DSM-IV-TR category among children and adolescents. Control the behavior based on what parents, teachers, or peer to expect is difficult for these children (Oltmanns \& Emery, 1995). Conduct Disorder is one of the most prevalence diagnosed disorder that according to DSM-IV-TR reflects as "repetitive and persistent pattern of behavior in which the basic rights of others or major age-appropriate societal norms or rules are violated" (American Psychiatric Association, 2000). Aggression toward people and animal, impulsive behavior, deceitfulness, and acting against rules are common among children with CD.

It is reported that this disorder affects between $6 \%$ to $16 \%$ of boys and $2 \%$ to $9 \%$ of girls in school-aged children (Pratt et al., 2003). Sarkhel, Sinha, Arora, and DeSarkar (2006) implemented a study in India for the prevalence of CD and reported as $4.58 \%$ of boys and $4.5 \%$ of girls with CD. This study stated that $36 \%$ of these children suffer from CD with mild severity and $64 \%$ with moderate severity. The study in Iran by Najafi, Foladchang, Alizadeh, and Mohamadifar (2009) presented the prevalence of behavioral disorders in Shiraz's city. It is revealed that between 1300 boys and girls at elementary school children, $17.8 \%$ of them affected by behavioral disorders. In addition, this study explained that 5\% of these children affected from CD. Azadyekta (2011) reported that the prevalence of CD in Tehran/Iran is 10.5\% among 2016 Primary school students.

Childhood onset type and adolescent onset type are two types of $\mathrm{CD}$ according to the classification of DSM-IV-TR. Childhood-onset type of CD is diagnosed when a child under 10 years-old shows at least one of the symptoms listed in DSM-IV-TR for CD. The main symptom of these children is aggressive behavior and poor peer relationship (Raine et al., 2005). When the child does not show any symptoms of CD prior 10 years old and after this age shows at least three symptoms, the adolescent-onset type of CD is diagnosed. Other disorders such as Attention Deficit Hyperactivity Disorder (ADHD) in 50\%, oppositional Defiant Disorder (ODD), anxiety, and depression have comorbidity with CD (American Psychiatric Association, 2000).

Among the types of aggression, it is reported that manifest aggression is more common among children with CD and the prevalence of it among boys is more than girls (Dodge \& Pettit, 2003). Two main types of manifest aggression include physical and verbal aggression (Coie \& Dodge, 1998). 
Coercive style in terms of physical and verbal pattern is common among family members of children with CD in the relationship of parent and child. For instance, these children experience more corporal punishment compare to other children. As a result, they learn to use force in family environment. Furthermore, when they learn aggressive behavior at home and use it in their personal relationship with other, they highly are rejected by them (Henry, Tolan, \& Gorman-Smith, 2001).

Social learning of Bandura (1977) supports this study. In this theory, it is stated that behavior is learned by two patterns; either observing similar behaviors or experiencing the outcomes of the behaviors. Children learn aggressive behavior in their family by observing them and face with the positive result of it. The other model that supports this study is Social Interaction Model presented by Patterson and his colleagues (Patterson, 1993; Gerald, Reid, \& Dishion, 1992). The significance of this model is on the role of peer relationships during childhood and adolescence. It focuses on the important role of maladaptive behavior during childhood. Furthermore, the development of this behavior later in adolescence is considered in this model.

As it mentioned above, aggressive behavior is the main sign of childhood onset type of CD. Arseneault, Kim-Cohen, Taylor, Caspi, and Moffitt (2005) conducted the study among children with CD between $41 / 2$ to 5 -year old on their behavioral problems. The findings of this study revealed that these children showed more aggressive and disruptive behavior in comparison to rule violation. Another study by Snyder, Horsch, and Childs (1997) focused on rejection experience among aggressive children. Non-aggressive children do not accept children with aggressive behavior and reject them. So, on the one hand, aggressive children do not have the opportunity of developing interpersonal skill. On the other hand, children with conduct problems and aggressive behavior are attracted to deviant peers. In addition, they reinforce each other's antisocial behavior (Kiesner, Dishion, \& Poulin, 2001). Aggressive behavior and rejection by peers can lead to other difficulties such as externalizing problems, internalizing problems, and poor academic performance. In case of externalizing problems, we can indicate about substance abuse and criminality. Internalizing problems refer to depression and low self-esteem. Poor academic skills are expressed as school dropout and grade retention (Hymel, Vaillancourt, McDougall, \& Renshaw, 2002; Kupersmidt \& DeRosier, 2004). Thus based on the importance of aggression and peer rejection among children with $\mathrm{CD}$, the aim of this study is to review previous studies worldwide and in Iran about aggression and peer rejection problems in children with $\mathrm{CD}$.

To end, first the methodology of the study is explained. Next, studies about aggression among children with CD are reviewed. Afterward, studies on peer rejection these children are reconsidered. Finally, studies in Iran regarding these two issues are presented and concluded with the summary of the study.

\section{Method}

This study is a kind of literature review that is entitled integrative reviews (Cooper, 1998). The current study attempted to summarize various results of library archives in peer rejection and aggression for children with Conduct Disorder. In addition, this study has a special focus on researches conducted in Iran about children with Conduct Disorder with suggestions and direction for furthere studies.

\section{Results}

In this section, studies about aggression and peer rejection among children with Conduct Disorder are reviewed worldwide and in Iran.

\subsection{Overview of Studies on Aggression between Children with Conduct Disorder}

Aggression is one of the series problems during childhood. If this important sign is ignored in this period, it might persist to adolescence and adulthood with antisocial behavior and deviant problems (Lochman, Powell, Whidby, \& Fitzgerald, 2006). There are numbers of studies that emphasized on the importance of aggression among children and the outcome as both violent and antisocial behaviors in adolescence (Haapasalo \& Tremblay, 1994; Miller-Johnson, Coie, Maumary-Gremaud, \& Bierman, 2002; Pope \& Bierman, 1999; Pulkkinen \& Tremblay, 1992). Finding of one study is reported on observing aggressive behavior among toddlers with the age between 18 to 24 months (Keenan \& Shaw, 1994). Another study by (Shaw, Keenan, \& Vondra, 1994) have stated on noncompliance of boys with 24 months with fewer responses to their mothers. A study by Keenan, Shaw, Delliquadri, Giovannelli, and Walsh (1998) have suggested about the relation between noncompliance in girls with 24 months with later externalizing problems between 3-5 years old. Moreover, this study demonstrated that boys with aggression in their 18 months may suffer from externalizing difficulties when they are between 3 to be 5 years old. Thus, it shows the early age of aggression among children.

Muntz, Hutchings, Edwards, Hounsome, and O'Céilleachair (2004) reported about increasing numbers of children with $\mathrm{CD}$. The signs of aggressive behavior among children with CD include lying, fighting, and 
physical cruel to people and animal (American Psychiatric Association, 2000). Moffitt et al. (2007) concerned with social development of childhood and adulthood of children with $\mathrm{CD}$ as a result of aggressive behavior and stated that $50 \%$ of children with CD suffer from aggression.

Little, Henrich, Jones, and Hawley (2003) focused on overt aggression and relational aggression among children with CD. As it explained above overt aggression include two types of physical and verbal aggression. This kind of aggression is more visible to boys. Relational aggression is related to harming other children with more prevalence among girls. It may happen by disturbing interpersonal relationship between friends.

Crick and Dodge (1994) explained the process of how children complete cognitive process when they tend to respond in a social situation to other children's behavior. It is identified as information processing. Children with aggressive behavior use different path to interpret perceived cues for interaction with others. They often recognize more threats in comparison to other children, slow in negotiation, and the number of response options is fewer and related to aggressive responses. The model of Social Information Processing (SIP) presented by Crick and Dodge (1994) to recognize how children decide and react in social environment. According to this model, children pass six steps to respond to social stimulus include: 1) encoding of cues (2) interpretation of cues (3) clarification of goals (4) response access or construction (5) response decision, and (6) behavioral enactment. Here it is not intended to explain all the six steps in details. However, the differences of children with aggressive behavior and conduct problems in each step are displayed. Children need external cues and internal knowledge based on their experiences for cue encoding. The distinction of aggressive children in this step is related to finding and chooses more cues associated with social conflict to encounter with their peers (Bugental, 1992; Crick \& Dodge, 1994).

Matthys, Cuperus, and Engeland (1999) examined the number of cues that children with Oppositional Defiant Disorder/Conduct Disorder, (ODD/CD), Attention Deficit Hyperactivity Disorder (ADHD), both disorders (ODD/CD+ADHD) encode in social situation. According to findings of this study child in three groups encoded fewer cues and related with aggression.

The cue interpretation for aggressive and rejected children is different from other children. Rejected children often have negative self-perception. However, non-rejected children have positive self-perception. Non-rejected children are connected negative events to external reasons and positive events to internal events. Although, rejected children are used the converse pattern for interpreting of positive and negative issues (Crick \& Dodge, 1994). Another difference of aggressive children in cue interpretation step with non-aggressive children is hostile attribution of intent among aggressive children. Rejection by peers and rough behavior of a parent in parenting style motivate aggressive children to respond with more hostile intent that leads to limitation in social interaction of them (Murray-Close et al., 2007).

Children select social goals based on general goal orientation and multiple social information processes in all steps (Crick \& Dodge, 1994). It is stated that social maladjusted children have difficulties with pursuing appropriate goals in specific social situation. They usually chose to damage goals instead of help to other peers to continue friendship that is common among well-adjusted children (Crick \& Dodge, 1994). Response action step of SIP is different for aggressive children in terms of number of and nature of responses they are produced. According to Crick and Dodge (1994) more aggressive responses found in ambiguous social situation among boys with ODD/CD. Response decision is constructed based on evaluating of response, expecting the outcomes and evaluation of self-efficacy. Aggressive and rejected children do these processes with more maladjusted behavior and aggressive response. One reason of aggressive responses among these children is low confident of them related to their abilities. They often think that by this process, it is more likely to generate positive and suitable outcomes (Crick \& Ladd, 1990).

So as it mentioned above, the social cognitive styles of aggressive and rejected children is different in terms of encoding fewer cues and with more hostile, misinterpreting of cues, responding with more hostile intent, generating antisocial goals and aggressive responses.

\subsection{Peer Rejection among Children with Conduct Disorder}

Although social competence is important for children to contact with their peers at school, children with the conduct problems do not have the opportunity for improve social competence. They are unpopular with their peers and usually receive negative nomination by them. In addition, teachers give them rate of noncompliance either in class or in the playground (Hektner, August, \& Realmuto, 2000; Olson, 1992). Children with aggressive behavior have learned to use force in their interpersonal relationship. For instance, they start to fight with other children. Developing externalizing pattern and poor social skills by children, the risk of rejection is increased among them. Actually, they lost the opportunity of friendship with children with prosocial behaviors (Hanish \& 
Guerra, 2002). In addition, aggression and peer rejection of these children at early age contribute more series conduct problems in late life. Study of Stormshak and Webster-Stratton (1999) explained that teachers of Elementary schools noticed children's aggression, disobedience, conflict of doing homework, problems with their peers and cooperating with them in order to rate children.

Guerra, Asher, and DeRosier (2004) examined the relation between perceived rejection and physical aggression among boys and girls in elementary school. They used sociometric assessment with questions of 'likes most', 'likes least', and 'who fights a lot'. The findings of this study were different between boys and girls. For the boys, results showed the relation between rejection and increasing in physical aggression for boys with aggressive behavior who had the tendency of blaming other peers in facing with social failure. The findings of study were emphasized on importance of self-perception of social rejection and its' effect on physical aggression. According to Hanish and Guerra (2002), the comparison of forms of friendship between boys and girls in elementary schools who are aggressive and rejected by their peers presented that boys with these behaviors looked for friends same as themselves with aggressive behavior and rejected. However, aggressive and rejected girls do not seek to find friends with similar behaviors and preferred to be lonely.

It is presented in the last part on rejection of children with $\mathrm{CD}$ by children with prosocial behavior and high risk of becoming friends with deviant peers. These findings also are confirmed by study of Fergusson, Swain-Campbell, and Horwood (2002) and study of Vitaro, Tremblay, and Bukowski (2001) on this issue. These studies demonstrated that some characteristics of children with CD such as personal, social, and family features of them strengthen the quality of friendship with deviant peers. Thus, both limited peer interaction opportunities in friendship with prosocial peers and friendship with deviant peers help to develop antisocial behavior among children with $\mathrm{CD}$.

To sum up, studies regarding aggression and peer rejection among children with conduct problems were reviewed. In the next part, Iranian studies among children with Conduct Disorder, especially about their aggression and peer rejection are presented.

\subsection{Studies in Iran among Children with Conduct Disorder}

Iranian studies about children with Conduct Disorder focused on the prevalence of these children in some main cities, survey on children's difficulties, and some kinds of treatment for them.

One study reported that $5 \%$ of children in Shiraz/Iran live with Conduct Disorder that $7.4 \%$ of them are boys, and 2.2\% are girls). This result confirmed the findings of previous studies such as (Pratt et al., 2003; Sarkhel, Sinha, Arora, \& DeSarkar, 2006; Ziaodini \& Shafizadeh, 2005) that the prevalence of CD among boys is more than girls. Ziaodini and Shafizadeh (2005) studied the epidemiology of Conduct Disorder in Sirjan/Iran between 18726 students in elementary schools between 7 to 11 years old. The teacher's report showed that $19.5 \%$ of children with CD were girls and $29.3 \%$ of boys were boys. This study emphasized on aggressive behavior among boys with CD. Another study in Kordestan/ Iran conducted for the prevalence of Conduct Disorder and ODD among 2760 boys and girls in guidance schools. This study reported that $6.3 \%$ of students were with CD and $6.9 \%$ with ODD. In addition, the results of this study displayed that there is a relation between aggressive behavior of parents, their family conflict and CD of students. It also mentioned that the prevalence of problems about interpersonal relationship between girls was more than boys (Yusefi, Erfani, Kheirabadi, \& Ghanei, 2000).

Other studies in Iran focused on intervention among children with CD., For instance; Hashemi, Eghbali, and Alilo (2009) examined the effect of verbal self-instruction on social adjustment between 20 students from Tabriz schools with Conduct Disorder. The findings of this study demonstrated that this program effect on social adjustment and interpersonal relation of children with CD. Another study investigated the effect of cognitive-behavioral play therapy on aggression among children with Conduct Disorder. The age range of aggressive boys with $\mathrm{CD}$ in this study was between 8 to 11 years old. The result of conducting cognitive-behavioral play therapy between 24 children demonstrated the reduction of aggression between them. This study emphasizes on the importance of deficits in social information processing among children with Conduct Disorder and its relation to aggressive behavior. They mentioned above the problem of these children in encoding step of SIP and the effect of it on choosing the aggressive response in social situations. They also indicated that children learned how to improve their social skills with peers by this intervention (Ghaderi, Asghari-Moghadam, \& Shaviri, 2006). The finding of this study was in line with the study of Baedi (2001) that conducted cognitive-behavioral play therapy in a group setting among boys between 7 to 11 years old with Conduct Disorder on their aggressive behavior.

As can be seen from above studies, Iranian researchers also investigated about the aggression and peer difficulties of children with Conduct Disorder. However, there is a lack of studies, specifically on peer rejection 
of children with aggressive behavior and conduct problems.

\section{Discussion}

This study reviewed previous researches about prevalence of Conduct Disorder, aggression and peer rejection among childhood onset type of children with CD. Aggression toward people and animal is the main problem of these children. They often used overt aggression with more prevalent among boys. Family style of them is considered as an important factor. It is explained that parents of children with CD often uses the coercive style, and children experienced corporal punishment. So the style of a family can affect negatively on pattern of children with their peers (Henry et al., 2001).

Iranian studies were reviewed in terms of investigation about prevalence of Conduct Disorder and some intervention for aggression and social problems of them. Two theories supported this study include social learning of Bandura (1977) and the role of peer relationship during childhood and adolescence of G.R. Patterson (1993). Aggressive behavior of children limits the opportunity of learning and developing social skills among prosocial peers; they often encounter rejection and feel negative self-perception. The reason of children's problem was explained based on cognitive deficits by model of Social Information Processing in encoding cues related to aggression, misinterpreting cues, hostile attribution of intent, choosing harm goals, and more aggressive responses.

As this study had a special focus on researches conducted in Iran about children with CD, it is suggested that in order to relieve for the effects of Conduct Disorder, especially aggression, peer rejection, antisocial behavior and deviant behavior of children at first and family of them, the schools and society, series programs and effective interventions for children, family, and schools should be considered. Parents of these children may feel stress to encounter with their child's difficulties at home. They need more information about CD and managing children's problems in terms of disruptive behavior, aggression, and parent-child relationship. Children with CD also need support to modify their behavior at home and interpersonal relationship. It is required that these children participate in the treatment program to prevent continuing problem to adolescence and adulthood.

\section{Acknowledgements}

We gratefully appreciate all the support and help received from numerous individuals to complete this research.

\section{References}

American Psychiatric Association. (2000). Diagnostic and statistical manual of mental disorders (4th ed.). Washington: DC: Author.

Arseneault, L., Kim-Cohen, J., Taylor, A., Caspi, A., \& Moffitt, T. E. (2005). Psychometric evaluation of 5-and 7-year-old children's self-reports of conduct problems. Journal of Abnormal Child Psychology, 33(5), 537-550. http://dx.doi.org/10.1007/s10802-005-6736-5

Azadyekta, M. (2011). Prevalence of Conduct Disorder among Elementary Students in Tehran City. Procedia-Social and Behavioral Sciences, 29, 693-702. http://dx.doi.org/10.1016/j.sbspro.2011.11.294

Baedi, Z. (2001). The effects of play therapy based on cognitive-behavioural therapy on decreasing aggression among children with conduct disorder. Journal of Thought and Behaviour, 25, 111-112.

Bandura, A. (1977). Social learning theory. New York: General Learning Press.

Bugental, D. B. (1992). Affective and cognitive processes within threat-oriented family systems.

Coie, J. D., \& Dodge, K. A. (1998). Aggression and antisocial behavior.

Cooper, H. M. (1998). Synthesizing research: A guide for literature reviews (Vol. 2). Sage Publications, Incorporated.

Crick, N. R., \& Dodge, K. A. (1994). A review and reformulation of social information-processing mechanisms in children's social adjustment. Psychological bulletin, $115(1), \quad 74$. http://dx.doi.org/10.1037/0033-2909.115.1.74

Crick, N. R., \& Ladd, G. W. (1990). Children's perceptions of the outcomes of social strategies: Do the ends justify being mean? Developmental psychology, 26(4), 612. http://dx.doi.org/10.1037/0012-1649.26.4.612

Dodge, K. A., \& Pettit, G. S. (2003). A biopsychosocial model of the development of chronic conduct problems in adolescence. Developmental psychology, 39(2), 349. http://dx.doi.org/10.1037/0012-1649.39.2.349

Fergusson, D. M., Swain-Campbell, N. R., \& Horwood, L. J. (2002). Deviant peer affiliations, crime and substance use: A fixed effects regression analysis. Journal of Abnormal Child Psychology, 30(4), 419-430. 
http://dx.doi.org/10.1023/A:1015774125952

Ghaderi, N., Asghari-Moghadam, M., \& Shaviri, M. (2006). Effect of cognitive behavioral play therapy on aggression among children with Conduct Disorder. Journal of scholar and behavior, 19, 75-84.

Guerra, V. S., Asher, S. R., \& DeRosier, M. E. (2004). Effect of children's perceived rejection on physical aggression. Journal of abnormal child psychology, 32(5), 551-563. http://dx.doi.org/10.1023/B:JACP.0000037783.88097.69

Haapasalo, J., \& Tremblay, R. E. (1994). Physically aggressive boys from ages 6 to 12: family background, parenting behavior, and prediction of delinquency. Journal of Consulting and Clinical Psychology, 62(5), 1044. http://dx.doi.org/10.1037/0022-006X.62.5.1044

Hanish, L. D., \& Guerra, N. G. (2002). A longitudinal analysis of patterns of adjustment following peer $\begin{array}{lllll}\text { victimization. Development and } & \text { 69-89. }\end{array}$ http://dx.doi.org/10.1017/S0954579402001049

Hashemi, T., Eghbali, A., \& Alilo, M. (2009). The effect of verbal self-instruction on social adjustment in children with Conduct Disorder. Journal of clinical psychology, 1(2), 29-36.

Hektner, J. M., August, G. J., \& Realmuto, G. M. (2000). Patterns and temporal changes in peer affiliation among aggressive and nonaggressive children participating in a summer school program. Journal of Clinical Child Psychology, 29(4), 603-614. http://dx.doi.org/10.1207/S15374424JCCP2904_12

Henry, D. B., Tolan, P. H., \& Gorman-Smith, D. (2001). Longitudinal family and peer group effects on violence and nonviolent delinquency. Journal of Clinical Child Psychology, 30(2), 172-186. http://dx.doi.org/10.1207/S15374424JCCP3002_5

Hymel, S., Vaillancourt, T., McDougall, P., \& Renshaw, P. D. (2002). Peer acceptance and rejection in childhood. Blackwell handbook of childhood social development, 265-284.

Keenan, K., Shaw, D., Delliquadri, E., Giovannelli, J., \& Walsh, B. (1998). Evidence for the continuity of early problem behaviors: Application of a developmental model. Journal of Abnormal Child Psychology, 26(6), 441-452. http://dx.doi.org/10.1023/A:1022647717926

Keenan, K., \& Shaw, D. S. (1994). The development of aggression in toddlers: A study of low-income families. Journal of Abnormal Child Psychology, 22(1), 53-77. http://dx.doi.org/10.1007/BF02169256

Kiesner, J., Dishion, T. J., \& Poulin, F. (2001). A reinforcement model of conduct problems in children and adolescents: Advances in theory and intervention. Conduct disorders in childhood and adolescence, 264-291.

Kupersmidt, J. B., \& DeRosier, M. E. (2004). How peer problems lead to negative outcomes: An integrative mediational model.

Little, T., Henrich, C., Jones, S., \& Hawley, P. (2003). Disentangling the "whys" from the "whats" of aggressive behaviour. International Journal of Behavioral Development, 27(2), 122-133. http://dx.doi.org/10.1080/01650250244000128

Lochman, J. E., Powell, N. R., Whidby, J. M., \& Fitzgerald, D. P. (2006). Aggressive Children: Cognitive-Behavioral Assessment and Treatment.

Matthys, W., Cuperus, J. M., \& Engeland, H. V. (1999). Deficient social problem-solving in boys with ODD/CD, with ADHD, and with both disorders. Journal of the American Academy of Child \& Adolescent Psychiatry, 38(3), 311-321. http://dx.doi.org/10.1097/00004583-199903000-00019

Miller-Johnson, S., Coie, J. D., Maumary-Gremaud, A., \& Bierman, K. (2002). Peer rejection and aggression and early starter models of conduct disorder. Journal of Abnormal Child Psychology, 30(3), 217-230. http://dx.doi.org/10.1023/A:1015198612049

Moffitt, T. E., Arseneault, L., Jaffee, S. R., Kim - Cohen, J., Koenen, K. C., Odgers, C. L., ... Viding, E. (2007). Research Review: DSM - V conduct disorder: research needs for an evidence base. Journal of Child Psychology and Psychiatry, 49(1), 3-33. http://dx.doi.org/10.1111/j.1469-7610.2007.01823.x

Muntz, R., Hutchings, J., Edwards, R. T., Hounsome, B., \& O'Céilleachair, A. (2004). Economic evaluation of treatments for children with severe behavioural problems. Journal of Mental health policy and Economics, 7(4), 177-189.

Murray-Close, D., Ostrov, J. M., Crick, N. R., Achenbach, T. M., Edelbrock, C. S., Berndt, T. J., ... Kaukianen, A. 
(2007). A short-term longitudinal study of growth of relational aggression during middle childhood: Associations with gender, friendship intimacy, and internalizing problems. Development and Psychopathology, 19(1), 187. http://dx.doi.org/10.1017/S0954579407070101

Najafi, M., Foladchang, M., Alizadeh, H., \& Mohamadifar, M. (2009). The prevalence of Attention Deficit Hyperactivity, Conduct Disorder, and Oppositional Defiant Disorder of elementary school aged children. Journal of Research on Exceptional Children, 3, 239-254.

Olson, S. L. (1992). Development of conduct problems and peer rejection in preschool children: A social systems analysis. Journal of Abnormal Child Psychology, 20(3), 327-350. http://dx.doi.org/10.1007/BF00916696

Oltmanns, T. F, \& Emery, R. E. (1995). Abnormal psychology. Prentice-Hall, Inc.

Patterson, G. R. (1993). Orderly change in a stable world: The antisocial trait as a chimera. Journal of Consulting and Clinical Psychology, 61(6), 911. http://dx.doi.org/10.1037/0022-006X.61.6.911

Patterson, G. R., Reid, J. B., \& Dishion, T. J. (1992). Antisocial Boys: A Social International Approach. Castalia.

Pope, A. W., \& Bierman, K. L. (1999). Predicting adolescent peer problems and antisocial activities: The relative roles of aggression and dysregulation. Developmental psychology, 35(2), 335. http://dx.doi.org/10.1037/0012-1649.35.2.335

Pratt, M., Smith, M., Reigelsperger, R., O'Connor, L. V., Saum, C., Baker, S., \& Reeb, R. N. (2003). Psychosocial treatment alternatives for adolescents with conduct problems. Journal of Psychological Practice; Journal of Psychological Practice.

Pulkkinen, L., \& Tremblay, R. E. (1992). Patterns of boys' social adjustment in two cultures and at different ages: A longitudinal perspective. International Journal of Behavioral Development, 15(4), 527-553. http://dx.doi.org/10.1177/016502549201500406

Raine, A., Moffitt, T. E., Caspi, A., Loeber, R., Stouthamer-Loeber, M., \& Lynam, D. (2005). Neurocognitive impairments in boys on the life-course persistent antisocial path. Journal of abnormal psychology, 114(1), 38. http://dx.doi.org/10.1037/0021-843X.114.1.38

Sarkhel, S., Sinha, V. K., Arora, M., \& DeSarkar, P. (2006). Prevalence of conduct disorder in schoolchildren of Kanke. Indian journal of psychiatry, 48(3), 159. http://dx.doi.org/10.4103/0019-5545.31579

Shaw, D. S., Keenan, K., \& Vondra, J. I. (1994). Developmental precursors of externalizing behavior: Ages 1 to 3. Developmental psychology, 30(3), 355. http://dx.doi.org/10.1037/0012-1649.30.3.355

Snyder, J., Horsch, E., \& Childs, J. (1997). Peer relationships of young children: Affiliative choices and the shaping of aggressive behavior. Journal of Clinical Child Psychology, 26(2), 145-156. http://dx.doi.org/10.1207/s15374424jccp2602_3

Stormshak, E. A., \& Webster-Stratton, C. (1999). The qualitative interactions of children with conduct problems and their peers: Differential correlates with self-report measures, home behavior, and school behavior

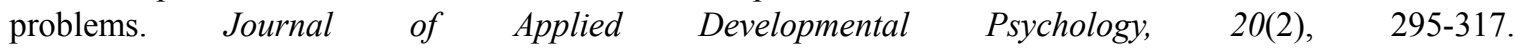
http://dx.doi.org/10.1016/S0193-3973(99)00018-0

Vitaro, F., Tremblay, R. E., \& Bukowski, W. M. (2001). Friends, friendships, and conduct disorders. Conduct disorders in childhood and adolescence, 346-378.

Yusefi, F., Erfani, N., Kheirabadi, G., \& Ghanei, H. (2000). Prevalence of conduct disorders and noncompliance among children in guidance school of Kurdestan state. Journal of Psychology and Educational Science, Thought, and Behaviour, 22, 48-54.

Ziaodini, H., \& Shafizadeh, N. (2005). Peer rejection and aggression and early starter models of conduct disorder. Journal of abnormal child psychology, 30, 217-320. 